Chapter 22

\title{
Increase in Thermal Stability of Proteins by Aprotic Ionic Liquids
}

\author{
Hidetaka Noritomi
}

Additional information is available at the end of the chapter

http://dx.doi.org/10.5772/51231

\section{Introduction}

Proteins are biomolecules of great importance in the biochemical processes such as the medical, pharmaceutical, and food fields, since they exhibit their outstanding biological activities under mild condition. However, most of proteins dissolved in an aqueous solution are immediately denatured and inactivated at high temperatures due to the disruption of weak interactions including ionic interactions, hydrogen bonds, and hydrophobic interactions, which are prime determinants of protein tertiary structures [5-3]. In particular, protein aggregation easily occurs upon the exposure of the hydrophobic parts of proteins, which are usually located in the inside of native proteins, and this phenomenon becomes the major problem because of the fast irreversible inactivation. Thermal denaturation of proteins is a serious problem not only in the separation and storage of proteins but also in the processes of biotransformation, biosensing, drug production, and food manufacturing. Several strategies have so far been proposed in order to prevent thermal denaturation of proteins [4-14]. They include chemical modification, immobilization, genetic modification, and addition of stabilizing agents. The addition of stabilizing agents is one of the most convenient methods for minimizing thermal denaturation, compared to other methods. It has been reported that inorganic salts, polyols, sugars, amino acids, amino acid derivatives, chaotropic reagents, and water-miscible organic solvents are available for improving protein stability. However, these additives do not sufficiently prevent irreversible protein aggregation or some of them are no longer stable at high temperatures.

Ionic solvent that is liquid at room temperature has attracted increasing attention as areen solvent for the chemical processes because of the lack of vapor pressure, the thermal stability, and the high polarity $[15,16]$. Chemical and physical properties of ionic liquids can be changed by the appropriate modification of organic cations and anions, which are constitu- 
ents of ionic liquids. It has recently been reported that protic ionic liquids such as alkylammonium salts keep the stability of proteins in an aqueous solution at high temperatures [17, 18], and amyloid fibrils of proteins are dissolved in protic ionic liquids and are refolded by dilution with an aqueous solution [19]. On the other hand, biotransformation in ionic liquids has increasingly been studied [20-2]. Aprotic ionic liquids such as immidazolium salts have mainly been employed as reaction media, since the high activity of enzymes is exhibited as usual. We have found that the activity of protease is highly maintained not only in waterimmiscible aprotic ionic liquids but also in water-miscible aprotic ionic liquids [23, 24].

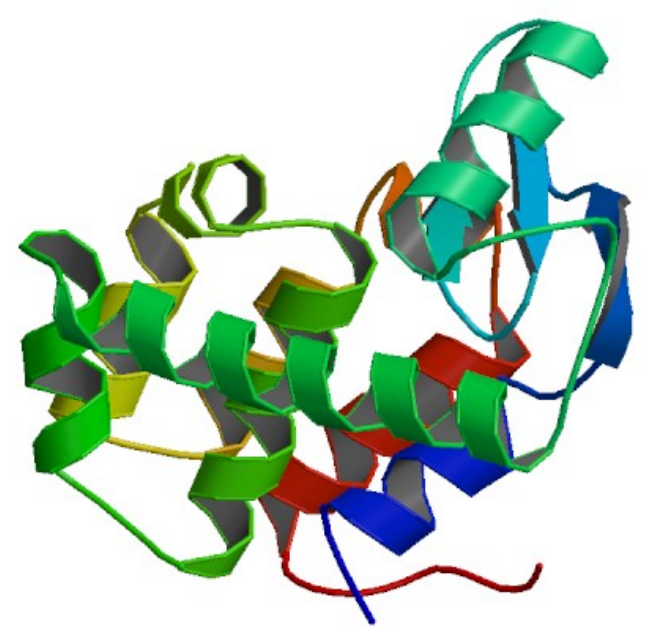

Figure 1. Structure of hen egg white lysozyme.

\begin{tabular}{|c|c|c|c|}
\hline Ionic liquid & Structure & m.p. & $\begin{array}{c}\text { Water } \\
\text { miscibility }\end{array}$ \\
\hline$[\mathrm{emim}][\mathrm{Tf}]$ & & -9 & Miscible \\
\hline$[\mathrm{emim}]\left[\mathrm{BF}_{4}\right]$ & Miscible \\
\hline$[\mathrm{emim}][\mathrm{Cl}]$ & 2 & 14.6 & Miscible \\
\hline
\end{tabular}

Figure 2. Structures of ionic liquids used in the present work. 


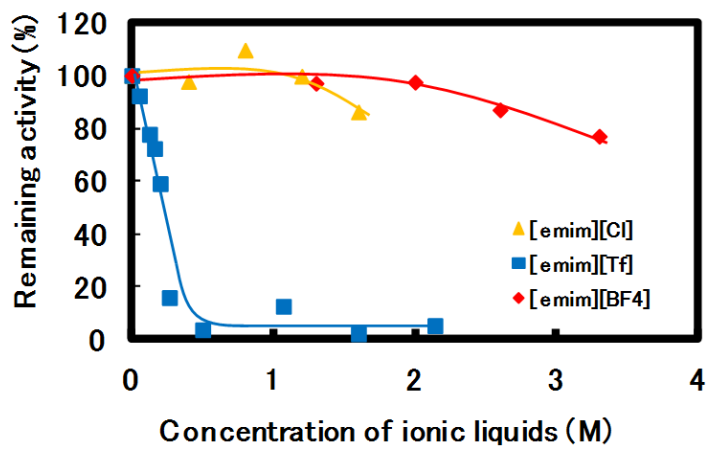

Figure 3. Effect of concentration of ionic liquids on remaining activity of lysozyme during incubation at $25{ }^{\circ} \mathrm{C}$. The aqueous solution of $100 \mu \mathrm{M}$ lysozyme with requisite concentration of ionic liquids was incubated in a water bath thermostated at $25^{\circ} \mathrm{C}$ for 30 min.

However, despite such potential capability of aprotic ionic liquids, there have not been any works on the thermal stability of proteins in aqueous solutions containing water-miscible aprotic ionic liquids.

In the chapter, the effect of water-miscible aprotic ionic liquids consisting of 1-ethyl-3-methylimidazolium cations and several kinds of anions on thermal stability of proteins in aqueous solutions is mainly discussed [25].

\section{Dependence of the remaining activity of lysozyme on the concentration of ionic liquids after the incubation at $25^{\circ} \mathrm{C}$}

As a model protein, hen egg white lysozyme has been employed as shown in Fig. 1, since it has been well investigated regarding its structure, properties, and functions [26]. Lysozyme is a compact protein of 129 amino acids which folds into a compact globular structure. The molecular weight of lysozyme is 14,300 , and the structure of lysozyme includes $\alpha$-helices, $\beta$ sheets, random coils, $\beta$ turns, and disulfide bonds, which are typical structures of proteins. Lysozyme attacks peptidoglycans in the cell walls of Gram-positive bacteria, and catalyzes hydrolysis of 1,4-beta-linkages between $\mathrm{N}$-acetylmuramic acid and $\mathrm{N}$-acetyl-D-glucosamine residues in a peptidoglycan. Accordingly, lysozyme has been used as an anti-inflammatory agent, a preservative, a freshness-keeping agent, an antibacterial agent, a disinfectant, and so on.

Room temperature ionic liquids of alkyl imidazolium cations are widely used, and are commercially available. Figure 2 shows structures and properties of ionic liquids introduced in this chapter. 1-Ethyl-3-methylimidazolium trifluoromethanesulfonate, 1-ethyl-3-methylimidazolium tetrafluoroborate, and 1-ethyl-3-methylimidazolium chloride are abbreviated to [emim][Tf], [emim] $\left[\mathrm{BF}_{4}\right]$, and [emim] $[\mathrm{Cl}]$, respectively. Their properties such as melting point alter by switching from one anion to another. 
It has been well known that ions and other compatible solutes affect enzyme activity [22]. Figure 3 shows the plot of the remaining activity of lysozyme against the concentration of ionic liquids after the incubation at $25^{\circ} \mathrm{C}$ for $30 \mathrm{~min}$. The remaining activity in the presence of $[\mathrm{emim}][\mathrm{Cl}]$ or $[\mathrm{emim}]\left[\mathrm{BF}_{4}\right]$ was independent on the concentration of ionic liquids till 1.2 $\mathrm{M}$ [emim] $[\mathrm{Cl}]$ or $2.0 \mathrm{M}$ [emim] $\left[\mathrm{BF}_{4}\right]$ and gradually dropped, while it in the presence of [emim][Tf] dramatically decreased with an increase in the concentration of [emim][Tf]. These results indicate that [emim][Tf] tends to strongly function as a denaturant, compared with $[\mathrm{emim}][\mathrm{Cl}]$ and $[\mathrm{emim}]\left[\mathrm{BF}_{4}\right]$. Electrolytes promote or inhibit the stability of proteins according to the kind of electrolytes [27-28].

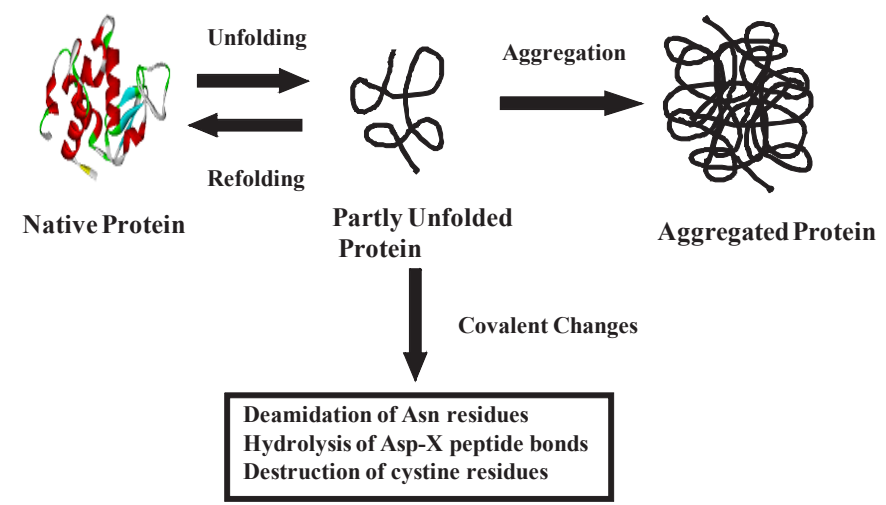

Figure 4. Schematic illustration of thermal denaturation of proteins.

\section{Thermal stabilization of lysozyme by aprotic ionic liquids}

\subsection{Thermal inactivation of lysozyme}

When proteins dissolved in an aqueous solution are placed at high temperatures, most of proteins are immediately unfolded due to the disruption of weak interactions including ionic effects, hydrogen bonds, and hydrophobic interactions, which are prime determinants of protein tertiary structures. In addition, the intermolecular aggregation among unfolded proteins and the chemical deterioration reactions in unfolded proteins proceed as shown in Fig. $4[2,29,30]$. In particular, protein aggregation easily occurs upon the exposure of the hydrophobic surfaces of a protein, and this phenomenon becomes the major problem because of the fast irreversible inactivation. On the other hand, when a heated solution of denatured proteins without protein aggregation is slowly cooled back to its normal biological temperature, the reverse process, which is renaturation with restoration of protein function, tends to occur. Accordingly, if stabilizing agents can sufficiently prevent irreversible aggregation of 
unfolded proteins, it is expected that unfolded proteins are refolded by cooling treatment, and the high remaining activity is obtained.

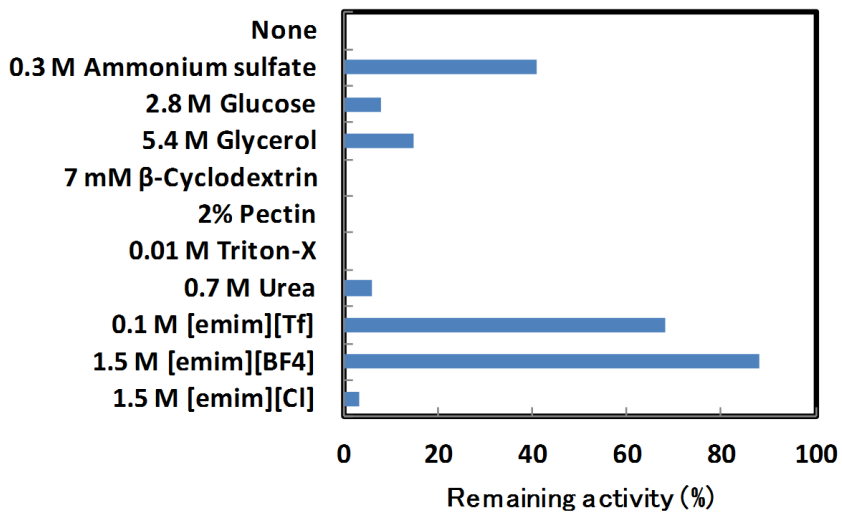

Figure 5. Remaining activities of lysozyme in the presence of various kinds of additives after heat treatment at $90{ }^{\circ} \mathrm{C}$ for $30 \mathrm{~min}$.

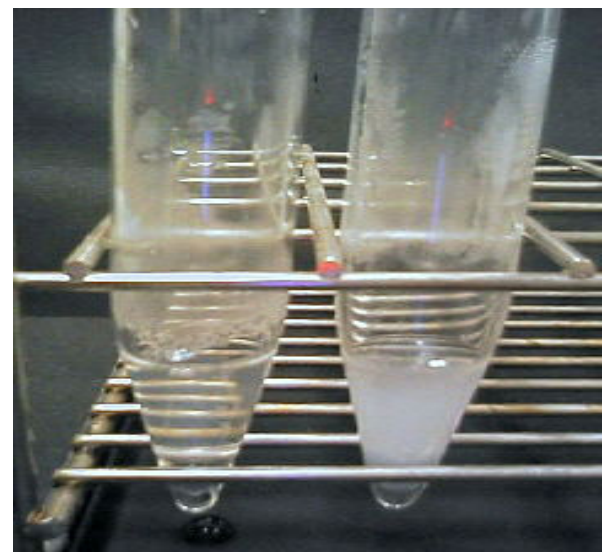

(a)

(b)

Figure 6. Photographs of lysozyme solutions after heat treatment at $90{ }^{\circ} \mathrm{C}$ for $30 \mathrm{~min}$ : (a) lysozyme solution with $1.5 \mathrm{M}$ [emim] $\left[\mathrm{BF}_{4}\right]$, (b) lysozyme solution without $\left[\mathrm{emim}^{\mathrm{m}}\right]\left[\mathrm{BF}_{4}\right]$.

Figure 5 represents the remaining activities of lysozyme in the presence of various kinds of additives after heat treatment at $90{ }^{\circ} \mathrm{C}$ for $30 \mathrm{~min}$ as an accelerated test. Lysozyme without additives lost its activity perfectly after heat treatment. Native lysozyme solution immedi- 
ately became turbid due to the aggregation of thermally-denatured proteins, as soon as heat treatment was carried out, as shown in Fig. 6(b). It has been reported that the precipitation due to protein aggregation at high temperatures is observed above $10 \mu \mathrm{M}$ lysozyme [31]. As lysozyme concentration in the present work was $100 \mu \mathrm{M}(1.4 \mathrm{mg} / \mathrm{mL})$ which was ten times higher than that, the formation of protein aggregation was dramatically accelerated. Ammonium sulfate, which was an inorganic salt, glucose and glycerol, which were polyols, and urea, which was a chemical denaturant, inhibited the formation of protein aggregation, and exhibited thermal stabilization to some extent. $\beta$-Cyclodextrin, which was an inclusion compound, pectin, which was a thickener, and Triton- $X$, which was a nonionic surfactant, could not maintain the stability of lysozyme at high temperatures, although they were widely used as a stabilizer. On the other hand, $[\mathrm{emim}]\left[\mathrm{BF}_{4}\right]$ and [emim][Tf] showed high remaining activities. The lysozyme solution in the presence of ionic liquids was transparent after heat treatment, as seen in Fig. 6(a). When lysozyme solution in the presence of protic ionic liquids such as alkylammonium formates is heated at $90{ }^{\circ} \mathrm{C}$, protein aggregation is prevented, and any cloudy appearance is absent [18]. The hydrophobic core of lysozyme unfolded by heat interacts with the cation of ionic liquids, and cation adsorption results in acquisition of a net positive charge preventing aggregation via electrostatic repulsion [17].

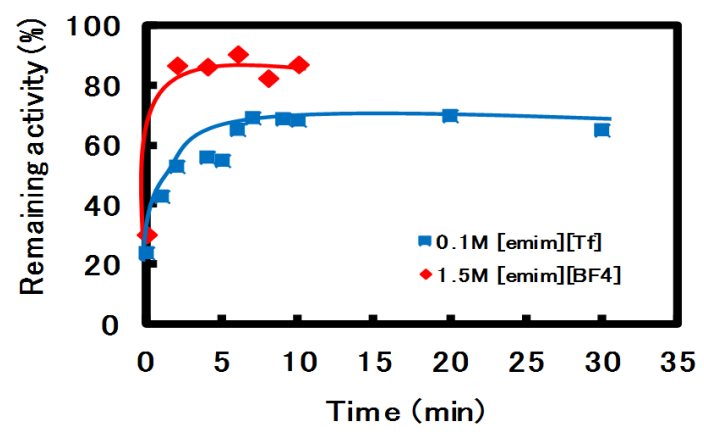

Figure 7. Time dependence of remaining activity of lysozyme with ionic liquids under cooling at $25^{\circ} \mathrm{C}$ after heat treatment at $90{ }^{\circ} \mathrm{C}$ for $30 \mathrm{~min}$. After heat treatment, the aqueous solution of $100 \mu \mathrm{M}$ lysozyme with $0.1 \mathrm{M}$ [emim][Tf] or 1.5 $\mathrm{M}[\mathrm{emim}]\left[\mathrm{BF}_{4}\right]$ was incubated in a water bath thermostated at $25^{\circ} \mathrm{C}$.

\subsection{Refolding of lysozyme by ionic liquids}

When the formation of protein aggregation is inhibited at high temperatures by ionic liquids, and thermally-denatured proteins are individually dispersed in an aqueous solution, it is probably that denatured proteins are gradually refolded under cooling conditions. Figure 7 shows the time course of remaining activity in the presence of ionic liquids under cooling treatment at $25{ }^{\circ} \mathrm{C}$ after the heat treatment at $90{ }^{\circ} \mathrm{C}$ for $30 \mathrm{~min}$. The remaining activities of lysozyme in the presence of $1.5 \mathrm{M}$ [emim] $\left[\mathrm{BF}_{4}\right]$ and $0.1 \mathrm{M}$ [emim][Tf] exhibited 30 and $24 \%$, respectively, just after heat treatment. The remaining activity of lysozyme with $1.5 \mathrm{M}$ 
[emim] $\left[\mathrm{BF}_{4}\right]$ or $0.1 \mathrm{M}$ [emim][Tf] rapidly increased with incubation time at $25{ }^{\circ} \mathrm{C}$, and reached a plateau around 2 and $7 \mathrm{~min}$, respectively. In sufficiently low concentration of proteins, where protein aggregation is not formed, when the hydrophobic core of proteins is exposed, but the disulfide bonds keep intact, denatured proteins gradually tend to refold to their native structures on cooling after thermal denaturation [32-36]. The refolding of thermally-denatured proteins is enhanced in the presence of protic ionic liquids such as alkylammonium nitrate and alkylammonium formates [32, 21]. Moreover, $\mathrm{N}^{\prime}$-alkyl and $\mathrm{N}^{\prime}-(\omega-$ hydroxyalkyl) $\mathrm{N}$-methylimidazolium chlorides refold denatured proteins such as hen egg white lysozyme and the single-chain antibody fragment ScFvOx [37].

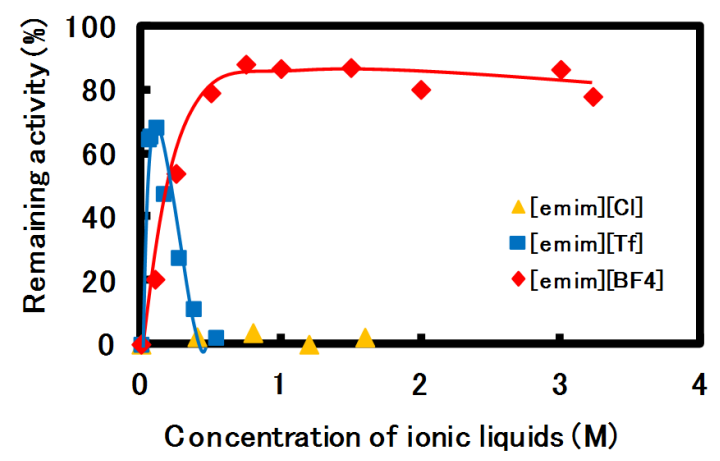

Figure 8. Effect of concentration of ionic liquids on remaining activity of lysozyme after heat treatment at $90{ }^{\circ} \mathrm{C}$ for 30 min. The aqueous solution of $100 \mu \mathrm{M}$ lysozyme with requisite concentration of ionic liquids was incubated in a silicone oil bath thermostated at $90{ }^{\circ} \mathrm{C}$ for $30 \mathrm{~min}$.

\subsection{Dependence of the remaining activity of lysozyme on the concentration of ionic liquids via heat treatment}

The stability of proteins depends upon the kind and concentration of electrolytes [27, 28]. Figure 8 shows the plot of the remaining activity of lysozyme against the concentration of ionic liquids after the heat treatment at $90{ }^{\circ} \mathrm{C}$ for $30 \mathrm{~min}$. The remaining activity was strongly dependent on the concentration of $\left[\mathrm{emim}^{-}\left[\mathrm{BF}_{4}\right]\right.$ or [emim][Tf], while the effect of concentration of $[\mathrm{emim}][\mathrm{Cl}]$ was not observed. The remaining activity in the presence of $[\mathrm{emim}]\left[\mathrm{BF}_{4}\right]$ increased with an increase in the concentration of $[\mathrm{emim}]\left[\mathrm{BF}_{4}\right]$ and reached a plateau around $0.8 \mathrm{M}$. The remaining activity in the presence of [emim][Tf] dramatically increased with increasing the concentration of [emim][Tf], the maximal remaining activity was obtained at 0.1 $\mathrm{M}$ [emim][Tf], and then decreased steeply. As seen in Fig. 3, the remaining activity decreased at $25{ }^{\circ} \mathrm{C}$ with an increase in the concentration of [emim][Tf]. Chemical denaturants, such as urea and guanidine hydrochloride, can promote dissolution of inclusion bodies, which are protein aggregation formed by prokaryotic expression systems [38]. Similarly, [emim][Tf] inhibits the formation of protein aggregation at low [emim][Tf] concentrations, but it mainly denatures proteins at higher [emim][Tf] concentrations. Moreover, it has been 
reported that after heat treatment the remaining activity of lysozyme increases with an increase in the concentration of ethylammonium formate and 2-methoxyethylammonium formate, while the remaining activity increases at low concentration of propylammonium formate, but at higher concentrations of propylammonium formate the protein spontaneously denatures [18]. Thus, the dependence of concentration of ionic liquids on the remaining activity of proteins changes by switching from one ionic liquid to another.

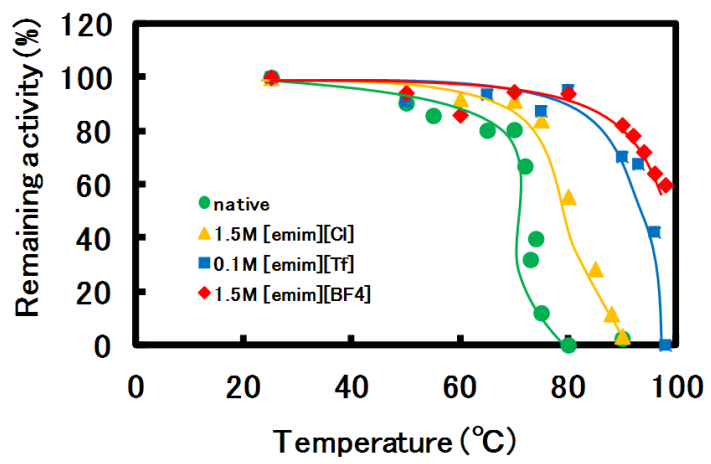

Figure 9. Thermal denaturation curves of lysozyme with or without ionic liquids. The aqueous solution of $100 \mu \mathrm{M}$ lysozyme with or without ionic liquids was incubated in a silicone oil bath thermostated at requisite temperature for 30 $\min$.

\subsection{Dependence of the remaining activity of lysozyme on the temperature of heat treatment}

The thermal inactivation of proteins more rapidly proceeds by higher temperatures. Figure 9 shows the relationship between the temperature of heat treatment and the remaining activity of lysozyme in aqueous solutions containing water-miscible ionic liquids after the heat treatment for $30 \mathrm{~min}$. As seen in the figure, the remaining activity of lysozyme without ionic liquids gradually decreased with an increase in temperature below $70{ }^{\circ} \mathrm{C}$, accompanied with the formation of precipitation due to protein aggregation, drastically dropped in the range from 70 to $80{ }^{\circ} \mathrm{C}$, and was then lost at temperatures of $80{ }^{\circ} \mathrm{C}$ or higher. The transition temperature was exhibited around $75{ }^{\circ} \mathrm{C}$, similar to the case measured by differential scanning calorimetry [17]. On the other hand, the remaining activity of lysozyme with $1.5 \mathrm{M}[\mathrm{emim}][\mathrm{Cl}]$ gradually decreased with an increase in temperature below $75{ }^{\circ} \mathrm{C}$, and drastically dropped in the range from 75 to $90{ }^{\circ} \mathrm{C}$. The remaining activity of lysozyme with $1.5 \mathrm{M}$ [emim] $\left[\mathrm{BF}_{4}\right]$ was highly maintained below $80{ }^{\circ} \mathrm{C}$, gradually decreased with temperature, and the remaining activity depicted $60 \%$ at $98{ }^{\circ} \mathrm{C}$. Similarly, the remaining activity of lysozyme with $0.1 \mathrm{M}$ [emim][Tf] was highly retained below $80^{\circ} \mathrm{C}$, gradually decreased with temperature below 92 ${ }^{\circ} \mathrm{C}$, drastically dropped in the range from 92 to $98^{\circ} \mathrm{C}$, and was then lost at $98{ }^{\circ} \mathrm{C}$. These results 
indicate that the addition of aprotic ionic liquids to an aqueous solution of lysozyme effectively improves the thermal stability of lysozyme at high temperatures.

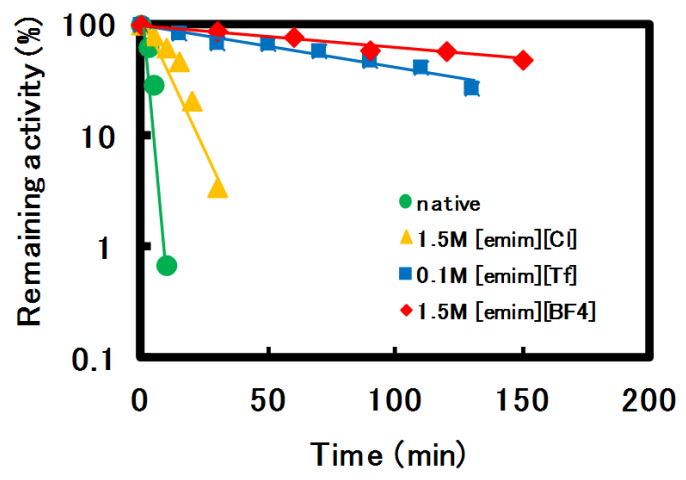

Figure 10. Time dependence of remaining activity with or without ionic liquids after heat treatment at $90{ }^{\circ} \mathrm{C}$. The aqueous solution of $100 \mu \mathrm{M}$ lysozyme with or without ionic liquids was incubated in a silicone oil bath thermostated at $90^{\circ} \mathrm{C}$.

\begin{tabular}{|c|c|c|}
\hline Ionic liquid & Rate constant $\left(\mathrm{min}^{-1}\right)$ & Half line ( $\min$ ) \\
\hline none & 0.43 & 1.6 \\
\hline $1.5 \mathrm{M}$ [emim][CI] & 0.065 & 22 \\
\hline $0.1 \mathrm{M}$ [emim][Tf] & 0.0081 & 86 \\
\hline $1.5 \mathrm{M}$ [emim] $\left[\mathrm{BF}_{4}\right]$ & 0.0049 & 141 \\
\hline
\end{tabular}

Table 1. Rate constants and half lives of inactivation of lysozyme at $90{ }^{\circ} \mathrm{C}$.

\subsection{Time course of remaining activity of lysozyme via heat treatment with or without ionic liquids}

Heating time directly enhances the thermal inactivation of proteins. Figure 10 shows time course of remaining activity of lysozyme with or without ionic liquids through the heat treatment at $90{ }^{\circ} \mathrm{C}$. The remaining activity of lysozyme without ionic liquids dramatically decreased with an increase in time, accompanied with the formation of protein aggregation, and was almost lost at $10 \mathrm{~min}$. It has been reported that the remaining activity in the thermal denaturation process accompanied with the formation of protein aggregation follows firstorder kinetics [31]. As seen in the figure, the relationship of the remaining activity of proteins in the absence of ionic liquids with the time of heat treatment could be correlated by first-order kinetics. On the other hand, $1.5 \mathrm{M}$ [emim] $\left[\mathrm{BF}_{4}\right]$ or $0.1 \mathrm{M}$ [emim][Tf] effectively prevented the thermal inactivation of lysozyme. In the presence of ionic liquids the turbidity 
of solutions due to protein aggregation was not observed during heat treatment. This indicates that the thermal inactivation mainly results from the covalent change as shown in Fig. 4. The plots of remaining activity versus heat treatment time on thermal inactivation of lysozyme in the presence of ionic liquids followed first-order kinetics on linearity. It has been reported that the thermal inactivation of lysozyme obeyed first-order kinetics when it irreversibly proceeded by the covalent change without the formation of protein aggregation [39]. Table 1 represents rate constants and half lives of inactivation of lysozyme with or without ionic liquids calculated from the fitting curves in Fig. 10. The half lives with $1.5 \mathrm{M}$ [emim] $\left[\mathrm{BF}_{4}\right], 0.1 \mathrm{M}$ [emim][Tf], and $1.5 \mathrm{M}$ [emim] $[\mathrm{Cl}]$ were 88,54 , or 6.9 times longer than that without ionic liquids, respectively.

\section{Conclusion}

In this chapter the effect of water-miscible aprotic ionic liquids on thermal stability of lysozyme has been described. Aprotic ionic liquids could sufficiently prevent thermally-denatured proteins from aggregating. The activity of lysozyme in the presence of aprotic ionic liquids was kept to some extent, just after heat treatment at high temperatures. Moreover, thermally-denatured lysozyme was effectively refolded by cooling. Consequently, the high remaining activity of lysozyme was obtained. These results indicate that aprotic ionic liquids act not only as an inhibitor of protein aggregation, but also as a protective agent in the native structure of protein and an accelerator in the refolding of thermally-denatured proteins. The remaining activity of lysozyme markedly depended upon the kind of anions and the concentration of ionic liquids. Especially, [emim][Tf] exhibited the thermostabilization effect of proteins at low concentrations, but mainly worked as a denaturant of proteins at high concentrations. The effect of $[\mathrm{emim}]\left[\mathrm{BF}_{4}\right]$ and [emim][Tf] upon thermal stabilization at high temperatures was much superior to that of [emim] [Cl]. As chemical and physical properties of ionic liquids can be changed by the appropriate modification of organic cations and anions, which are constituents of ionic liquids, it is expected that the ionic liquid, which is more suitable for the thermal stabilization of proteins, is prepared by tailoring the constituents of ionic liquids.

\section{Author details}

Hidetaka Noritomi $^{1}$

1 Tokyo Metropolitan University Japan 


\section{References}

[1] Ballesteros, A., Plou, F. J., Iborra, J. L., \& Halling, P.J. (1998). Stability and Stabilization of Biocatalysts, Elsevier, Amsterdam.

[2] Volkin, D.B., \& Klibanov, A.M. (1989). Minimizing protein inactivation. Protein Function: Practical Approach, 1-24, IRL Press, Oxford.

[3] Klibanov, A.M. (1983). Stabilization of enzymes against thermal inactivation. Adv. Appl. Microbiol., 29, 1-28.

[4] Illanes, A. (1999). Stability of biocatalysts. Electro. J. Biotechnol., 2, 1-9.

[5] Noritomi, H., Kai, R., Iwai, D., Tanaka, H., Kamiya, R., Tanaka, M., Muneki, K., \& Kato, S. (2011b). Increase in thermal stability of proteins adsorbed on biomass charcoal powder prepared from plant biomass wastes. J. Biomedical, Sci. Eng., 4, 692-698.

[6] Gerlsma, S.Y. (1968). Reversible denaturation of ribonuclease in aqueous solutions is influenced by polyhydric alcohols and some other additives. J. Biological Chem., 243, 957-961.

[7] Kaushik, J.K., \& Bhat, R. (1998). Thermal stability of proteins in aqueous polyol solutions: role of the surface tension of water in the stabilizing effect of polyols. J. Phys. Chem. B, 102, 7058-7066.

[8] Back, J. F., Oakenfull, D., \& Smith, M. B. (1979). Increased thermal stability of proteins in the presence of sugars and polyols. Biochemistry, 18, 5191-5196.

[9] Lee, J. C., \& Timasheff, S.N. (1981). The stabilization of proteins by sucrose. J. Biological Chem., 256, 7193-7201.

[10] Santoro, M.M., Liu, Y., Khan, S.M.A., Hou, L.X., \& Bolen, D.W. (1992). Increased thermal stability of proteins in the presence of naturally occurring osmolytes. Biochemistry, 31, 5278-5283.

[11] Yancey, P.H., Clark, M.E., Hand, S. C., Bowlus, R.D., \& Somero, G.N. (1982). Living with water stress: evolution of osmolyte systems. Science, ${ }_{, 1} 217,1214-1222$.

[12] Arakawa, T., Bhat, R., \& Timasheff, S.N. (1990). Why preferential hydration does not always stabilize the native structure of globular proteins. Biochemistry, 29, 1924-1931.

[13] Ikegaya, K. (2005). Kinetic analysis about the effects of neutral salts on the thermal stability of yeast alcohol dehydrogenase. J. Biochemistry, 137, 349.

[14] Cioci, F., \& Lavecchia, R. (1998). Thermostabilization of proteins by water-miscible additives. Chem. Biochem. Eng. Q., 12, 191-199.

[15] Welton, T. (1999). Room-temperature ionic liquids. Solvents for synthesis and calalysis. Chem. Rev., 99, 2071-2083. 
[16] Greaves, T.L., \& Drummond, C.J. (2008). Protic ionic liquids: properties and applications. Chem. Rev., 108, 206-237.

[17] Summers, C.A., \& Fowers, I. I. R. A. (2000). Protein renaturation by the liquid organic salt ethylammonium nitrate. Protein Sci., 9, 2001-2008.

[18] Mann, J.P., Mc Cluskey, A., \& Atkin, R. (2009). Activity and thermal stability of lysozyme in alkylammonium formate ionic liquids- influence of cation modification. Green Chem., 11, 785-792.

[19] Byrne, N., \& Angell, C. A. (2009). Formation and dissolution of hen egg white lysozyme amyloid fibrils in protic liquids. Chem Comm., 1046-1048.

[20] Moniruzzaman, M., Nakashima, K., Kamiya, N., \& Goto, M. (2010). Recent advances of enzymatic reactions in ionic liquids. Biochem. Eng. J., 48, 295-314.

[21] Yang, Z., \& Pan, W. (2005). Ionic liquids: Green solvents for nonaqueous biocatalysis. Enz. Microbial Technol., 37, 19-28.

[22] Zhao, H. (2011a). Effect of ions and other compatible solutes on enzyme activity, and its implication for biocatalysis using ionic liquids. J. Mol. Catal. B: Enzymatic, 37, $16-25$.

[23] Noritomi, H., Nishida, S., \& Kato, S. (2007). Protease-catalyzed esterification of amino acid in water-miscible ionic liquid. Biotechnol Lett., 29, 1509-1512.

[24] Noritomi, H., Suzuki, K., Kikuta, M., \& Kato, S. (2009). Catalytic activity of $\alpha$-chymotrypsin in enzymatic peptide synthesis in ionic liquids. Biochem. Eng. J., 47, 27-30.

[25] Noritomi, H., Minamisawa, K., Kamiya, R., \& Kato, S. (2011b). Thermal stability of proteins in the presence of aprotic ionic liquids. J. Biomedical Sci. Eng., 4, 94-99.

[26] Jollès, P. (1996). Lysozymes:. Model Enzymes in Biochemistry and Biology., Birkhäuser Verlag, Basel.

[27] Von Hippel, P.H., \& Schleich, T. (1969). The effects of neutral salts on the structure and conformational stability of macromolecules in solution. Structure and Stability of Biological Macromolecules, 417-574, Marcel-Dekker, New York.

[28] Nostro, P.L., \& Ninham, B.W. (2012). Hofmeister phenomena: an update on ion specificity in biology. Chem. Rev., 112, 2286-2322.

[29] Lumry, R., \& Eyring, H. (1954). Conformation changes of proteins. J. Phys. Chem., 58, 110-120.

[30] Zale, S.E., \& Klibanov, A.M. (1983). On the role of reversible denaturation (unfolding) in the irreversible thermal inactivation of enzymes. Biotechnol. Bioeng, 25, 2221-2230.

[31] Nohara, D., Mizutani, A., \& Sakai, T. (1999). Kinetic study on thermal denaturation of hen egg-white lysozyme involving precipitation. J. Biosci. Bioeng., 87, 199-205. 
[32] Ibara-Molero, B., \& Sanchez-Ruiz, J.M. (1997). Are there equilibrium intermediate states in the urea-induced unfolding of hen egg-white lysozyme? Biochemistry, 36, 9616-9624.

[33] Griko, Y.V., Freire, E., Privalov, G., Dael, H.V., \& Privalov, P.L. (1995). The unfolding thermodynamics of c-type lysozyme- a calorimetric study of the heat denaturation of equine lysozyme. J. Mol. Biol., 252, 447-459.

[34] Privalov, P.L., \& Khechinashvili, N.N. (1974). A thermodynamic approach to the problem of stabilization of globular protein structure. J. Mol. Biol., 86, 665-684.

[35] Khechinashvili, N.N., Privalov, P.L., \& Tiktopulo, E.I. (1973). Calorimetric investigation of lysozyme thermal denaturation. FEBS Lett., , 30, 57-60.

[36] Anfinsen, C.B. (1973). Principles that govern the folding of protein chains. Sci., 181, 223-230.

[37] Lange, C., Patil, G., \& Rudolph, R. (2005). Ionic liquids as refolding additivesN'-alkyl and $N^{\prime}-(\omega$-hydroxyalkyl) N-methylimidazolium chlorides. Protein Sci., 14, 2693-2701.

[38] Rudolph, R., \& Lilie, H. (1996). In vitro folding of inclusion body proteins. FASEB J., $10,49-56$.

[39] Ahern, T.J., \& Klibanov, A.M. (1985). The mechanism of irreversible enzyme inactivation at $100{ }^{\circ} \mathrm{C}$. Science, $228,1280-1284$. 
